ISSN: 2641-1725

\title{
Influence of Body Mass Index to Avert Non-Communicable Diseases
}

\author{
Sarvananda $\mathbf{L}^{1,3 *}$, Menusha umayangani ${ }^{2}$ and Ajith Janaka karunaratne ${ }^{3}$ \\ ${ }^{1}$ Department of Botany, Faculty of Sciences, Sri Lanka \\ ${ }^{2}$ Ayurvedic medical hospital, Kotmale Sri Lanka \\ ${ }^{3}$ Tejana Higher Educational Institute, Sri Lanka \\ *Corresponding author: Sarvananda L, Department of Botany, Faculty of Sciences, Peradeniya, Sri Lanka
}

\begin{abstract}
Non-communicable diseases (NCDs) are highly challenges to this world due to several reasons such as emerging trendurbanization, lifestyle transformations, and related factors. Individually and cumulatively, the epidemiological, demographic and socioeconomic transitions are fueling a surge in NCDs, which now account for $65 \%$ of all deaths in the country. Our review study has followed Literature survey method used to analysis how body mass index contributes to controlling progression of noncommunicable disease from various database. The burden of chronic non-communicable diseases (NCD) cannot reduce without equitable access to essential medicines. NCD medicines are critical for the treatment of cardiovascular diseases, diabetes, chronic respiratory diseases, and many type of cancers, mental and neurological disorders. Meanwhile, demand for medicines is growing rapidly along with the rising number of NCD patients. So, this review shows that body mass index can cure or stop the progression of non-communicable diseases by maintain healthy life pattern by following regular food habit and good physical activities. These studies suggests that maintaining body mass index (BMI) by following good healthy diet with physical activities can cure or stop progressive of non-communicable diseases
\end{abstract}

Keywords: Public health; Life pattern; BMI; NCDs; Height; Weight

\section{Introduction}

As per many findings, NCDs are the leading cause of death globally. In 2012, it was recorded as $60 \%$ to $68 \%$ of all deaths in 2000. About half were under the age of 70 and women population was high [1]. Every year, at least 5 million people die because of tobacco consumption and about 2.8 million die from being obese. At the same time, the death rates of Hypercholesteremia patients are roughly calculated as 2.6 million to 7.5 million because of high blood pressure [2]. There are several reasons resulting this, emerging trend-urbanization, lifestyle transformations, and related factors might be person's background, lifestyle, genetics errors in genetic information and environmental factors such as sunlight, nutrition, exposure to air pollution, which can affect people, are known to increase the certain non-communicable diseases. It also includes age, gender, and unwanted behaviors like smoking, unhealthy diet and physical inactivity which can leads to increased risk of many NCDs [3]. According to World Health Report in 2002, they identified five important risk factors increasing the level of noncommunicable diseases in health environment. They are raising blood pressure, cholesterol, tobacco use, alcohol consumption, and overweight/obesity. The other factors associated with higher risk of NCDs include a person's economic and social conditions.

The most common causes for non-communicable diseases (NCD) include tobacco use (smoking), alcohol abuse, poor diets (high consumption of sugar, salt, saturated fats, and Trans fatty acids) and physical inactivity. Formerly, NCDs kill approximately 36 million people per annum; it might be expected to rise by $17-24 \%$ within the next decade [4]. Given the global population distribution, almost $80 \%$ of deaths due to chronic NCDs worldwide now occur in 
low and middle-income countries, while only $20 \%$ occur in higher income countries. National economies are allegedly suffering important losses because of premature deaths or inability to work resulting from heart disease, stroke and diabetes [5]. The rate due to presenteeism is likely even larger, while methods of analyzing the economic impacts of presenteeism are still being developed [6]. A trend has emerged, particularly in the early 2000s, in which numerous studies have revealed a link between fast food and an increase in heart disease [7].

\section{Body Mass Index (BMI)}

Body Mass Index (BMI) can be defined as a simple index of weight-for-height that is basically used to for categorizing underweight, overweight and obesity in adults. It is defined as the weight in kilograms divided by the square of the height in meters $(\mathrm{kg} / \mathrm{m} 2)$. BMI values are age-independent and the same for both sexes. However, BMI might not correspond the similar of obesity in different populations due to different body proportions. The health risks associated with increasing BMI are continuous and the interpretation of BMI grading in relation to risk may differ with different populations $[8,9]$ (Table 1).

Table 1: The International Classification of adult underweight, overweight and obesity according to BMI.

\begin{tabular}{|c|c|c|}
\hline \multirow{2}{*}{ Classification } & \multicolumn{2}{|c|}{ BMI(kg/m2) } \\
\cline { 2 - 3 } & $\begin{array}{c}\text { Principal cut-off } \\
\text { points }\end{array}$ & $\begin{array}{c}\text { Additional cut-off } \\
\text { points }\end{array}$ \\
\hline Underweight & $<\mathbf{1 8 . 5 0}$ & $<\mathbf{1 8 . 5 0}$ \\
\hline Severe thinness & $<16.00$ & $<16.00$ \\
\hline Moderate thinness & $16.00-16.99$ & $16.00-16.99$ \\
\hline Mild thinness & $17.00-18.49$ & $17.00-18.49$ \\
\hline \multirow{2}{*}{ Normal range } & $\mathbf{1 8 . 5 0}-\mathbf{2 4 . 9 9}$ & $\mathbf{1 8 . 5 0}-\mathbf{2 2 . 9 9}$ \\
\cline { 2 - 3 } & $\geq \mathbf{2 5 . 0 0}$ & $\mathbf{2 3 . 0 0}-\mathbf{2 4 . 9 9}$ \\
\hline Overweight & \multirow{2}{*}{$25.00-29.99$} & $25.00-27.49$ \\
\hline \multirow{2}{*}{ Pre-obese } & $\geq \mathbf{3 0 . 0 0}$ & $27.50-29.99$ \\
\hline Obese & \multirow{2}{*}{$30.00-34.99$} & $\geq 30.00$ \\
\hline \multirow{2}{*}{ Obese class I } & \multirow{2}{*}{$35.00-39.99$} & $32.50-34.99$ \\
\hline \multirow{2}{*}{ Obese class II } & $\geq 40.00$ & $35.00-37.49$ \\
\hline Obese class III & & $37.50-39.99$ \\
\hline \multirow{2}{*}{} & & $\geq 40.00$ \\
\hline
\end{tabular}

\section{Importance of BMI}

Weighty and obesity are increased crosswise all age sets, including preschool-aged children. Having a healthy body weight is important to all people, especially children, to optimize their health outcomes. Overweight and obesity are associated with greater health risks, even in young children. Low weight is occasionally an indicator of poor health or sickness. However, most "thin" children are healthy $[10,11]$. In general, exists of overweight and obesity carries a greater threat to long-term health than being "underweight". Maintaining a proper and healthy weight helps children to have a better self-esteem and confidence, improves participation in sport and active play and improves sleep. Health experts can accomplish vital role in promoting a healthy weight in children [12].

\section{Health and Social Risks}

Weighty and obesity are having an excess of adipose tissue (body fat). We need a certain quantity of body fat for normal, healthy functioning of the body. However, an excess of body fat is detrimental to our health [13], Childhood weighty and obesity can have direct effects. However, most young weighty children seem healthy. Traditionally it was believed that overweight in young children would be "grow out of it" or "baby fat", but this is not now generally the case. Unless weight is managed effectively, we know that most weighty children become weighty adults, and this can result in long term health problems [14].

\section{Research Problem}

Sri Lanka today faces several new challenges. The country is in an advanced stage of a demographic transition with the life expectancy of 71 yrs. for males and 78 yrs. for females. At the same time, the epidemiological transition is shifting the disease burden from communicable diseases to what is popularly known as "lifestyle disease". These are known as a non-communicable disease (NCDs) including cardiovascular diseases (such as heart attacks and stroke), cancers, chronic respiratory diseases (such as chronic obstructed pulmonary disease and asthma) and diabetes. There are several reasons for this emerging trend-urbanization, lifestyle transformations, and related factors. Individually and cumulatively, the epidemiological, demographic and socioeconomic transitions are fueling a surge in NCDs which now account for $65 \%$ of all deaths in the country. Among these NCD-related deaths, 25\% are occurring prematurely before the age of 60yrs (world health statistics 2011).

\section{Relation of BMI in NCDs}

Normally, BMI range should be at 18.5 to 24.9. When BMI range becomes more than 24.9 there is a chance to cause NCDs. This is mainly because of the changes in their life style, nutrition and physical \& mental activities such as less physical activities, consuming high calorie foods full of saturated fat and sugar, intake of fizzy drinks, highly consuming alcohol, and tobacco uses. When BMI range is below than 18.5 they have associated with health complications such as bone loss, decreased immunity cardiac problems and also there is evidence that even modest weight loss (5-10\%) can reduce cardiovascular disease risk even when the patients remains in the obese range [15-19], infertility, and iron deficiency anemia. Except these, environment factor and genetics also contribute a high level of risk to NCDs such as exposure to air pollution. Cancer is preventable via avoiding risk factors including: tobacco, being overweight or obesity, low fruit and vegetable intake, physical inactivity, alcohol, sexually transmitted infections, 
and air pollution Diabetes Mellitus Type 2 can be cure with dietary management, exercise, medications, Patient education, understanding, and participation. Wider health problems may accelerate the deleterious effects of diabetes. These include smoking, elevated cholesterol levels, obesity, high blood pressure, and lack of regular exercise.

\section{Conclusion}

Developing countries, today faces new challengers and are subjected to a higher rate of death due to non-communicable diseases. It includes environmental factor such as emerging trend urbanization, life styles transformations and related factor. Our studies shows that maintaining a Body Mass Index (BMI) range between from 18.5 to 24.9 can cure or reducing progression of NonCommunicable Diseases (NCDs). So that if we could take several actions to educate and change the world to a system which includes NCD/disease national plans for all, a tobacco free world, improved lifestyles, strengthened health systems, global admission to reasonable and good quality medicines and technologies and Human rights for people with NCDs can cure or control the progressive of the lifestyles diseases. Moreover, to maintain the Body Mass Index a suitable and healthy life pattern should be practiced that is to intake a variety of fruits, vegetables, and grain in the everyday meal and increase physical activities, avoiding unwanted behavior such as tobacco use, alcoholism, fizzy drinks and fast food, Drinking plenty of water which is recommended by government, and stress management by mediation, yoga and counseling.

\section{Acknowledgement}

We would first take the opportunity to thank our internal guide, Dr. Janaka karunaratne, Director of Tejana Higher educational institute (clinic health unit), Paradeka, for providing necessary facilities to write this review article.

\section{References}

1. (2015) The top 10 causes of death. World Health Organization.

2. (2016) Noncommunicable diseases. World Health Organization

3. Sarvananda L, Menusha umayangani, Janaka karunaratne (2017) Potential uses of ancient herbal preparations against non-communicable diseases". Journal of Medicinal Plants Studies 5(5): 142-145.
4. (2011) Non-Communicable Diseases Deemed Development Challenge of 'Epidemic Proportions' in Political Declaration Adopted During Landmark General Assembly Summit. United Nations. Department of Public Information.

5. (2015) YP-CDN. Purpose. YP-CDN.

6. (2005) ab Preventing Chronic Diseases a Vital Investment. Cataloguingin-Publication Data. World Health Organization.

7. Cancer (2011) World Health Organization, p. 1-9.

8. WHO (1995) Physical status: the use and interpretation of anthropometry. Report of a WHO Expert Committee. WHO Technical Report Series 854. Geneva: World Health Organization.

9. WHO (2000) Obesity: preventing and managing the global epidemic. Report of a WHO Consultation. WHO Technical Report Series 894 Geneva: World Health Organization pp. 252.

10. WHO/IASO/IOTF (2000) The Asia-Pacific perspective: redefining obesity and its treatment. Health Communications Australia: Melbourne, Australia.

11. James WPT, Chen C, Inoue S (2002) Appropriate Asian body mass indices? Obesity Review 3(3): 139.

12. WHO expert consultation (2004) Appropriate body-mass index for Asian populations and its implications for policy and intervention strategies. Lancet 363(9403): 157-163.

13. TJ Cole, MC Bellizzi, KM Flegal, WH Dietz (2000) Establishing a standard definition for child overweight and obesity worldwide: international survey. BMJ 320(7244): 1240-1243.

14. Bahat G, Tufan F, Saka B, Akin S, Ozkaya H, et al. (2012) Which body mass index (BMI) is better in the elderly for functional status? Archives of Arch Gerontol Geriatr 54(1) 78-81.

15. Stevens VJ, Obarzanek E, Cook NR, Lee IM, Appel LJ, et al. (2001) Long term weight loss and changes in blood pressure: results of the trails of Hypertension Prevention, phase II. Ann Intern Med 134(1): 1-11.

16. Wing RR (2010) Long-term effects of a lifestyle intervention on weight and cardiovascular risk factors in individuals with type 2 diabetes mellitus: four-year results of the Look AHEAD trial. Arch Intern Med 170(17): 1566-1575.

17. Goldstein DJ (1992) Beneficial health effects of modest weight loss. Int J Obes Relat Metab Disord 16(6): 397-415.

18. Vidal J (2002) Updated review on the benefits of weight loss. Int J Obes Relat Metab Disord. 26(Suppl 4): S25-S28.

19. Knowler WC, Barrett Connor E, Fowler SE, Hamman RF, Lachin JM, et al. (2002) Reduction in the incidence of type 2 diabetes with lifestyle intervention or metformin. N Engl J Med 346(6): 393-403.

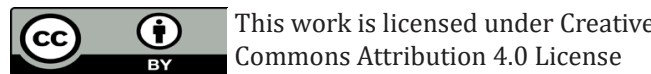

To Submit Your Article Click Here: Submit Article

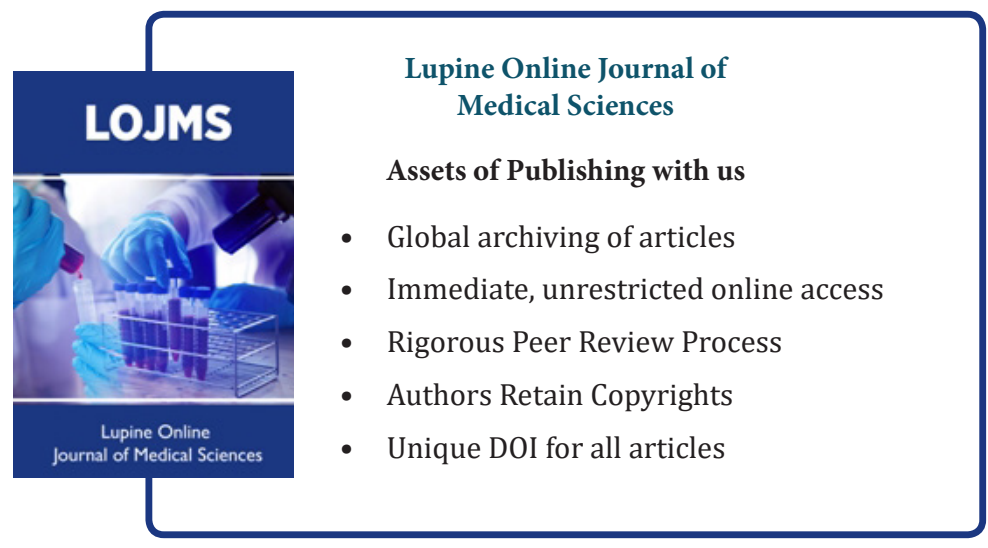

Citation: Sarvananda L, Menusha u, Ajith Janaka k. Influence of Body Mass Index to Avert Non-Communicable Diseases. LOJ Med Sci 2(5)- 